\title{
A Research on Different Models for E-Learning
}

\author{
Pujari Vinayak, Manali Londhe, R.B. Patil
}

\begin{abstract}
This paper is survey of the crucial fashions of e-learning procedure. The various fashions are actualized numerous functions in e-analyzing. wide scope of e-learning hypotheses and models are advancing ordinary as in keeping with the location of e-gaining knowledge of and getting to know scenario. right here we have précised a portion of the important models that are utilized by numerous scientists for instructive innovation improvement to make the most of possibilities to create compelling analyzing methodologies amongst understudies for dealing with web statistics over-burden and fluctuating records best. indeed, extremely good instructing infers glaringly that, so as to create powerful college students, educators need to be unmistakable. those models assumes giant system for e-getting to know machine development and improvement.
\end{abstract}

Keywords: E-getting to know, educational technology net statistics, information best, effective student.

\section{INTRODUCTION}

E-learning is the usage of information improvement in the educating and gaining knowledge of manner. Enlightening development is the convincing use of mechanical gadgets in studying. educational development is not confined to excessive development .despite the fact that, virtual informative development, furthermore called e-mastering, has transformed right into a massive little little bit of society in recent times. E-gaining knowledge of consists of a huge use of digitization approachs, sections and movement methodologies. for example, m-gaining knowledge of stresses convenientce except is commonly uncertain on a vital degree from informative innovation. Informative development fuses certainly one of a type types of media that skip on substance, sound, photographs, development, and spilling video, and joins development programs and techniques, for example, sound or video tape, satellite tv for pc television, CD-ROM, and pc based adapting, similarly as nearby intranet/extranet and net primarily based mastering. data and correspondence systems, paying little admire to whether unsupported or trouble to both nearby frameworks or the net in masterminded gaining knowledge of, underlie diverse e-getting to know structures. fashions of e-reading depict wherein improvement performs an precise hobby in supporting studying. these may be depicted each at the element of informational measures and on the problem of

Revised Version Manuscript Received on 16 September, 2019.

Mr. PujariVinayak, Research Scholar, Department of Computer science and engineering, Shri JJTU, Rajasthan, India.

(email: vinayakpujari86@gmail.com)

Dr. ManaliLondhe, Principal,Department of Computer science and engineering, S.K.Somaiya College of Arts, Science and Commerce, Mumbai, Maharashtra, India.

(email: drminalilondhe@gmail.com)

Dr. R.B. Patil, Professor, Department of Computer science and engineering, S.K.Somaiya College of Arts, Science and Commerce, Mumbai, Maharashtra, India.

(email: patilrajendrab@gmail.com) natty abrasive exercising in knowledge the ones norms. As such the fashions may be used to grow new structures and to examine superior reading through this techniques. This paper lines some exceptional and transformative fashions used for e-getting to know and development of e-reading process.

The utilization of e-mastering and emulsified studying maintains on extending basically in steering in Bharat at gift. there's a longing to recognise where, once and below what situations on line and emulsified getting to know can be applied efficiently and authorized in the instructing and gaining knowledge of technique every understudy ought to have the enthusiasm for recognizing what's occurring inside the beauty as quickly as the educate is teaching and take an interest in getting to know system. The mental variables like aspect and pinnacle rate are pretty full-size components obligated for a success getting to know. The accomplishment of on-line and emulsified studying is predicated upon the education degree of the researchers. on the point at the same time as the researchers create accept as proper with of their capacity to be instructed and their best aspect regulate them to perform high of their language accomplishment. This research is probably a distinct study objectives searching on the adequacy of exploitation e-learning on the brink and exuberance of the understudies in mastering the language. Understudies from the city and semi urban territories discovering in building faculties were assigned higgledy piggledy for the examination. The designing faculties were maximum well-gotten a kick out of the danger to Arts faculties due to the prerequisite for reinforcing relational competencies is extraordinarily fundamental for constructing graduates to fight at the overall degree for differed occupations. Survey containing factor scale and pinnacle magnificence scale became wont to acquire facts concerning exploitation e-mastering for upgrading language gaining. mastering collected have become investigated measurably. The effects of the examination have positioned that there may be a measurably important qualification (zero.05 stage) between the city and semi urban understudies in exploitation e-getting to know for upgrading relational talents. strengthened the consequences, the examiner has superior a few hints and proposition for upgrading language learning.

\subsection{Definition:}

The conveyance of a selecting up, training or training program with the aid of the usage of digital proposes that. E-gaining knowledge of includes the usage of a pc or gadget (as an example a mobile cellphone) in a manner to deliver teaching, scholarly or learning cloth. (Derek Stockley 2003) 


\section{2 importance of E-reading:}

E-gaining knowledge of has without a doubt numerous edges over vintage studying approach. may be both partner degree nonconcurrent or synchronous motion: without a doubt, e-studying has been offbeat, which recommends there's no organized time for the education to require area. anybody will go at their personal pace, and take as an lousy lot time as critical to discover what they need to get a manipulate on, once they must fathom it. nevertheless, a top notch deal of synchronous e-getting to know is as of now being furnished via internet conferencing and talk alternatives. The tremendous issue concerning e-learning is it offers you the choice to try and do one, or each.

carries a worldwide reach: E-learning will truly be positioned on-line and basically gotten to through using people round the sector. there's no might probable want for past an low cost doubt obtained journey or gatherings over diverse time zones.

ranges exclusive devices/transportable: on line courses will address computers moreover as on cellular phones, as an example, cellular telephones and tablets. This suggests e-mastering guides will for all intents and purposes be inside the fingers of the who need them, even the slightest bit times.

inside the nick of time/needs-based totally totally: it is functionality to make, distribute, and percent a direction among severa hours. The product is extremely easy to utilize that pretty plenty all people will create sharing publications.

Lessens charges: the entire going earlier than elements result in a worth reserve price range for institutions that utilization E learning guides to switch some of their antiquated educator drove training.

1.3 kinds of E-getting to know:

1. Synchronous making equipped

2. Offbeat making prepared

1. Synchronous, implies at the equal time,\| consists of cooperation of members with an educator thru the internet constantly. as an example - VCRs or digital have a look at halls which are not anything else besides for real homerooms on the net. individuals partner with one another and instructors through texting, communicate, sound and video conferencing and so on and what's all of the greater every one of the lessons may be recorded and done back. Its blessings are: capacity to log or tune mastering wearing occasions. constant watching and treatment is capability possibilities of world network and cooperation openings among students. capacity to customize the preparation for every pupil.

2. Nonconcurrent because of this no longer simultaneously permits the contributors to complete the WBT (net primarily based getting prepared) at their very own pace, without live communique with the educator. basically, it's far facts that is open on a self development premise, all day, every day. The little bit of leeway is this kind of e-mastering gives the scholars the data they need at some thing element they need it. It furthermore has cooperation amongst people via message sheets, announcement sheets and communique discussions. those incorporate pc based totally getting prepared; (CBTs) modules on CD-ROM's, internet based totally making equipped had been given to through intranet (WBTs) or thru elegantly composed articles and different opinions. Its factors of hobby are:- to be had inside the nick of time for 2nd gaining knowledge of and reference.
Adaptability of access from everywhere whenever. ability to all the whilst arrive at a boundless type of representatives. Consistency of substance and onetime charge of introduction.

\section{LITURATURE SURVEY}

thought frameworks territory unit one kind of sifting statistics and giving the advanced crucial information to the consumer. this will provide idea to the clients with the records that area unit genuinely essential to the patron. idea frameworks vicinity unit most usually utilized in prescribing item in on line shops and in department shops. There territory unit severa explores are achieved to present idea administrations upheld patron behavior.

inspiration framework is a vivacious space of examination and a few investigations have been performed to make use of this in prescribing books, track, movies, recordings, information, and websites for searching information. within the version prepared by way of the articles territory unit guided upheld the measurable positions of patron intrigue. There territory unit 4 training of steering framework:

i) Rule-primarily based keeping apart, any region clean standards were utilized

ii) Cooperative preserving aside - the clients may be counseled subjects that people with a proportionate tastes and dispositions preferred within the past.

Iii) content-based totally - the clients can be suggested things that place unit just like the one which the consumer most properly-loved inside the beyond. this may offer terrible very last consequences whilst the complete customers sector unit heterogeneous and restrained.

Iv) Hybrid framework - consolidates each useful and substance based totally methodologies. Ontologies are performed to a scope of recommender frameworks to curtail content material heterogeneousness and improve content healing.

A developing digital learning framework which also can adjust to the open net in light of the usage of its studying substances is organized thru craftsman. Personalization is that the subsequent degree in the improvement of eLearning frameworks. Understudies should have numerous subjective structures that make the electricity associate in nursing effectuality of an eLearning framework truly superb with specific understudies. gathering pastime the three virtually particular development in the area of e-getting to know vicinity unit educational method (pupil foreordained educational speculations), even minded (practical answers for usage of instructive additives by way of way of teachers and instructive creators), and mechanical want to be viable exploitation mysticism. Transcendentalism are frequently carried out for records outline. besides in electricity we are able to suggest how one factor in related to various topics and it pretty difficult to fuse the scholars read and score. records mining might be acclimated separate the records from E-studying framework like Moodle. The path idea framework in e-studying might be a framework that suggests the satisfactory blend of guides internal which the researchers have a pinnacle rate.

Published By:

Blue Eyes Intelligence Engineering 
facts mining strategies are frequently acclimated recommend the super combination of guides. some e-getting to know suggestion frameworks get acquainted with the students' gain, mentality and need of times, and signify them as low capability, mild functionality and excessive ability college college students and supporter the studying way thusly and multiple numerous come to be familiar with the student's benefit, standpoint and need from their profile.

\section{E-MASTERING MODELS\& RESULTS}

1. Demand-pushed version(macdonald - 2001)

2. Strategic e-mastering version

3. E-getting to know acceptance model

4. Educational plan model

5. E-gaining knowledge of existence - cycle version

\section{CONCLUSION}

This paper condenses the summed up fashions of e-learning. As regards to the prerequisite of the research take a look at mastering requirements, the models might be criminal and coordinated. Those paper gives brief association with regard to execution of e-gaining knowledge of models for e-mastering be with reference to hypotheses of e-mastering viable look at the models for express research paintings as an example fashions for business e-gaining knowledge of, essential getting to know, instructional models, internet learning fashions and later on on. The relative studies of these fashions can likewise be allocated for growth examination and to investigate estimations of those models for specific e-getting to know.

\section{REFERENCES}

1 Alexander, s 2001. E-gaining knowledge of upgrades and encounters. Instruction and education, bradford 43(four-5):240-248

2 Elearning basics, lesson2-theories and fashions of e-inclining toward a a success structure for the assessment of e-learning ,tom franklin, franklin consulting jill

3 Armstrong, ltsn and liverpool desire university university martin oliver, college university londonjimpetch, university of manchester.

4 Alook at e-mastering fashions: examination in their functions for e-studying manner

5 Blignaut, s. And trollip, s. (2003). A taxonomy for school participation in asynchronous on-line discussions. In $\mathrm{d}$. Lassner and c. Mcnaught (eds.), court cases of edmedia: international convention on academic media and era 2003 (pp. 2043-2050). Courting for the development of computing in training (aace).

6 Graham attwell (ed.),a manual to theevaluation of e-gaining knowledge of,evaluateeurope handbook collection volume 2

7 Govindasamy, $\mathrm{t}$ 2002. Effective usage of e-learning: instructional contemplations. Web and better education 4:287-299.

8 Fayed g.s.d., h., jihad.,m., alja'am, samir, a.s., and hosam, e. (2006). E-gaining knowledge of version depending on semantic internet innovation. Ordinary diary of figuring and facts sciences, 4(2), sixty 3 - seventy one

9 Nothing, d. (2005). Instructional models for e-analyzing: a speculation primarily based totally shape device. Normal diary of innovation in educating and getting to know, 6(3), 25-44.

10 Tsai, m.- j. (2009). The version of strategic e-studying: expertise and comparing pupil e-mastering from metacognitive views. Instructive generation and society, 12 (1), 34-48.

11 Vital version of imposing e-gaining knowledge of mohamedjamamadar, dr. Osowillis, worldwide

12 Diary of scientific and era research quantity 3, issue five, might also 2014 issn 2277-8616,235, ijstr@2014.clarke, t and hermens, a 2001. Company improvements and key collusions in e-getting to know. Instruction and education (bradford) 43(four-five): 256-267.

13 Tsai, m.- j. (2009). The version of strategic e-getting to know: information and evaluating scholar e-learning from metacognitive views. Instructive generation and society 12 (1), 34-48.

14 Venkatesh, v. What is extra, davis, f.d. "a theoretical extension of the technology recognition model: four

15 Longitudinal field research," control technology, 46, 2000, 186-204. [

16 Fayed g.s.d., h., jihad., m., alja'am, samir, a.s., and hosam, e. (2006). E-studying model relying on semantic internet innovation. Global diary of registering and facts sciences, $4(2)$, sixty three - seventy one

17 Lifestyles systems of an elearning lesson: 9 activities of education, blog with the aid of shelley a. Gabl

18 Gagne r, briggs 1, guess w, editors. 1/3 launch. The big apple: holt, rinehart and winston; 1998. Requirements of educational plan.

19 Step by means of step instructions to utilize gagne's version of tutorial plan in showing psychomotor capabilities,kayvankhadjooi, 1

20 Kamran rostami,2 and sauid ishaq2 gastroenterolhepatol bed bench. 2011 summer time; 4(three): 116-119.

21 Battalion, d. R. (2011). E-getting to know inside the 21st century: a gadget for research and exercising (second edition).london: routledge/falmer.

22 Morrison, gary r. Making plans effective preparation, 6th edition. John wiley and sons, 2010.

23 Wilson, b.g., jonassen, d.h., and cole, p. (1993) Psychological aproaches to academic form. The astdhanbook of instructional innovation, 21.1-21.22). The big apple: mcgraw-hill. April 22, 2005.

24 The addie version: educational layout posted in frameworks and theories on january 29, 2014 by manner of ed forest.

25 Tripp,steven, bichelmeyer,barbara, rapid prototyping: an alternative academic plan technique, instructional technology studies and improvement, 38, 1, three/18/1990, pages 31-forty four. 